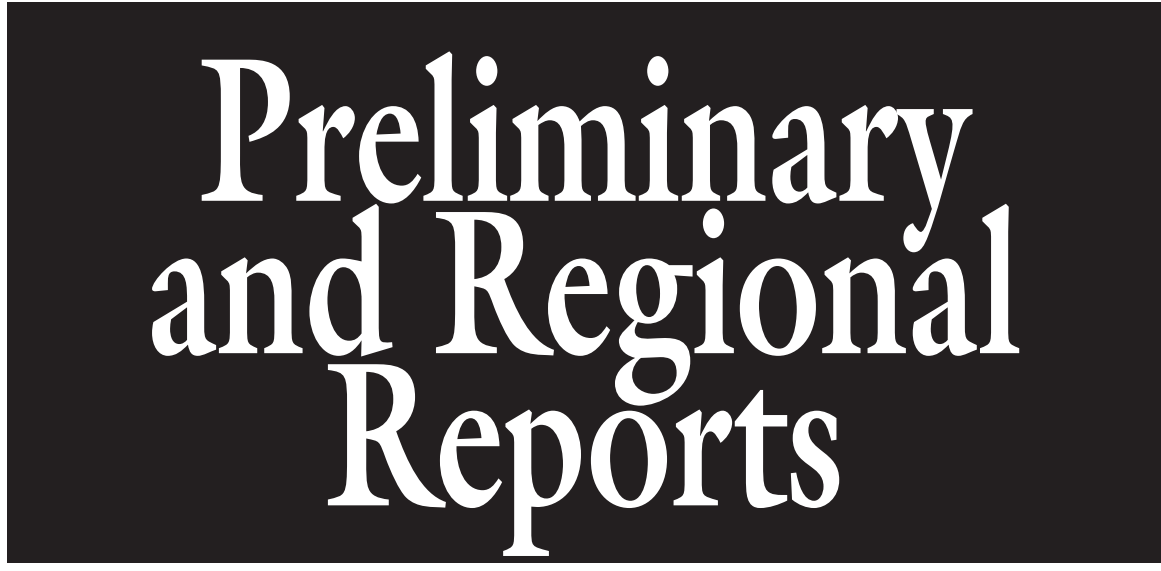

\section{Blackberry Propagation by Non-leafy Floricane Cuttings}

\author{
Fumiomi Takeda ${ }^{1,4,8}$, Thomas Tworkoski ${ }^{1,5}$, Chad E. Finn ${ }^{2,6}$, \\ and Charles C. Boyd ${ }^{3,7}$
}

AdDitionAl INDEX WORDs. Rubus, adventitious root, cytokinin, axillary bud, enclosure system

SuMmaRY. One- or two-node hardwood cuttings were taken from 9-year-old 'Triple Crown' and 'Siskiyou' blackberry (Rubus) plants on 5 Nov. 2009, 3 Dec. 2009, and 21 Jan. 2010. The response of cuttings with and without partially excised axillary buds to an application of cytokinin was compared with control cuttings with intact axillary buds and no cytokinin. Differences in root development were evident in the two cultivars tested. The cuttings of 'Siskiyou' and 'Triple Crown' callused on cut ends, but many of the adventitious roots developed from the base of the axillary buds. Shoots emerged from the bud in $\approx 90 \%$ of 'Siskiyou' cuttings stuck in November, December, and January. Rooting occurred in more than $90 \%$ of cuttings stuck in November and December but declined in cuttings stuck in January. In 'Siskiyou', bud excision had no effect on shoot and root emergence, but cytokinin treatment suppressed rooting in cuttings collected in November and January. Shoot emergence and rooting were poorer in 'Triple Crown' cuttings than in 'Siskiyou'. In 'Triple Crown' cuttings, partial excision of buds reduced shoot emergence only in January but had no effect on rooting at three sticking dates. Cytokinin treatment improved shoot emergence in November and December but reduced rooting in January. The enclosed system is a viable method for propagating 'Siskiyou' blackberry by non-leafy floricane cuttings.

$\mathrm{B}$ lackberry traditionally has been propagated using vegetative methods including tip layering,

\footnotetext{
Appreciation is expressed to Mary Peterson, Franklin Adams, and Ann Rose for their technical assistance.

${ }^{1}$ Appalachian Fruit Research Station, USDA-ARS, 2217 Wiltshire Road, Kearneysville, WV 25430

${ }^{2}$ Horticultural Crops Research Laboratory, USDAARS, 3420 NW Orchard Avenue, Corvallis, OR 97331

${ }^{3}$ Cedar Valley Nursery, Inc, 3942 McElfresh Road SW, Centralia, WA 98531

${ }^{4}$ Research Horticulturist and Lead Scientist

${ }^{5}$ Supervisory Plant Physiologist

${ }^{6}$ Research Geneticist

${ }^{7}$ Owner and Plant Propagator

${ }^{8}$ Corresponding author. E-mail: fumi.takeda@ars.usda.
} gov.

cane cuttings (soft and hard), root cuttings, and tissue culture (TC) (Caldwell, 1984). Large commercial blackberry nurseries use TC techniques that are expensive and need a high capital investment, but a few small nurseries are still using leafy softwood cuttings taken in summer from stock plants

\begin{tabular}{llll}
\hline $\begin{array}{l}\text { Units } \\
\text { To convert U.S. to SI, } \\
\text { multiply by }\end{array}$ & U.S. unit & SI unit & $\begin{array}{l}\text { To convert SI to U.S., } \\
\text { multiply by }\end{array}$ \\
\hline 29.5735 & $\mathrm{fl} \mathrm{oz}$ & $\mathrm{mL}$ & 0.0338 \\
0.3048 & $\mathrm{ft}$ & $\mathrm{m}$ & 3.2808 \\
2.54 & $\mathrm{inch}(\mathrm{es})$ & $\mathrm{cm}$ & 0.3937 \\
33.9057 & $\mathrm{oz} / \mathrm{yard}{ }^{2}$ & $\mathrm{~g} \cdot \mathrm{m}^{-2}$ & 0.0295 \\
1 & $\mathrm{ppm}$ & $\mathrm{mg} \cdot \mathrm{L}^{-1}$ & 1 \\
$\left({ }^{\circ} \mathrm{F}-32\right) \div 1.8$ & ${ }^{\circ} \mathrm{F}$ & ${ }^{\circ} \mathrm{C}$ & $\left(1.8 \times{ }^{\circ} \mathrm{C}\right)+32$
\end{tabular}

growing in screen house to propagate blackberry plants (J. Ballington, personal communication). Propagation of some erect-type blackberries by softwood cuttings and root pieces appear feasible (Busby and Himelrick, 1999; Thompson et al., 2004; Zimmerman et al., 1980). Propagation of blackberry by hardwood or floricane stem cuttings has been reported, but the results have been poor and variable $(<50 \%$ rooting) (Bray et al., 2003; Lopez-Medina and Moore, 1997; Zimmerman et al., 1980). Treatment of blackberry cuttings with indolebutyric acid (IBA) has given mixed results (Busby and Himelrick, 1999; Zimmerman et al., 1980). Rooting in hardwood cuttings occurred at the base of the cuttings, but the cause of poor rooting in some cultivars was attributed to overwatering (Zimmerman et al., 1980). Each of the traditional nonTC methods has its disadvantages. Tip-layering technique is laborious and the ratio of new transplants produced per stock plant is usually low (Hartmann et al., 1997). To root leafy, softwood material, the cuttings must be stuck in root media and misted intermittently for several weeks. For commercial acceptance of a propagation method, stock plants must produce plant material in large numbers, and the collection and handling of propagation material must be cost effective. A simple, inexpensive method that will generate high numbers of rooted cuttings is preferred.

Rooting leafy cuttings of ornamental crops with one to several nodes can be done in enclosed systems (Hartmann et al., 1997), in which watered-in cuttings are placed in plastic tents without intermittent misting using the following environmental conditions: rooting media temperature of 18 to $25^{\circ} \mathrm{C}$, atmosphere that is conducive to low water loss, and light level that is not excessive. Rooting of hardwood cuttings under a plastic tent without mist was reported to be as good as rooting under intermittent 
mist in some thornless blackberry (Zimmerman et al., 1980). In a preliminary study, several adventitious roots developed at the base of most axillary buds on five-node hardwood cuttings of 'Siskiyou' with their base submersed in water and stored in sealed plastic bags (F. Takeda, personal observation).

Flower bud initiation in blackberry occurs in the fall. Floral primordia in trailing blackberry (e.g., 'Siskiyou') differentiate in the fall, but floral primordia in eastern thornless blackberry (e.g., 'Triple Crown') are not visible until spring (Takeda et al., 2002; Takeda and Wisniewski, 1989). The presence of an actively growing shoot tip is necessary during the first 3 or $4 \mathrm{~d}$ after the cuttings are made for root formation to occur (Hartmann et al., 1997), but if the apical meristem that is already reproductive is left intact on hardwood blackberry cuttings, the shoots that emerge during propagation likely will end in flowers. Excising the distal half to two-third of the axillary bud should remove the differentiated meristem. Cytokinin application to buds favors shoot formation and inhibits root initiation in stem cuttings, but in decapitated pea (Pisum satioum) cuttings, cytokinins at very low concentrations promoted root initiation (Erickson, 1974; Heide, 1965).

One objective of this study was to assess whether one-node and twonode hardwood cuttings of 'Siskiyou' and 'Triple Crown' could be rooted in an enclosure system. A second objective was to determine the effects of cytokinin application and bud removal on adventitious root and shoot (flowering and vegetative) development in hardwood cuttings collected in winter.

\section{Materials and methods}

Lateral canes were collected in Nov. 2009, Dec. 2009, and Jan. 2010 from 9-year-old 'Siskiyou' (Finn et al., 1999) and 'Triple Crown' (Galletta et al., 1998) blackberry plants trained on the rotating cross-arm trellis system at the Appalachian Fruit Research Station, Kearneysville, WV (Takeda et al., 2003). The crossarms were positioned upright in summer and the lateral canes were tied to wires on the cross-arm as they grew vertically and were tipped at $6 \mathrm{ft}$ or when they grew 4 inches beyond the topmost wire. In late fall, the crossarms with the lateral canes of 'Siskiyou' were rotated downward and oriented horizontally 20 inches above the ground and a floating rowcover (1.5 oz/yard ${ }^{2}$; Altmore Industries, Altmore, AL) was installed over the plants in early December to reduce winter injury (Takeda et al., 2008). The lateral canes of 'Triple Crown' plants remained in a vertical orientation and were not protected in winter. Each month, five or more lateral canes were harvested from five 'Siskiyou' and five 'Triple Crown' plants. The canes were made into two-node cuttings in November and into one-node cuttings in December and January. The axillary buds were either left intact or the distal half to two-third of the bud was excised. The bases of the axillary bud on half of the cuttings in each group (intact or excised buds) were dabbed with a cotton swab dipped in either $0.87 \mathrm{~mm}$ (196 ppm) 6 -benzyladenine or water. Cuttings were placed in the following rooting media: in 250-mL beakers with $1 \mathrm{~cm}$ of water in November, in 50-cell pack flats filled with moist peat-based media in December, or in moistened 102-count foam growing media (Oasis Wedge ${ }^{\circ}$; Smithers-Oasis, Kent, $\mathrm{OH})$. The beakers and trays were put in clear plastic bags, and the bags were closed to maintain high humidity and held at room temperature $(20$ $\left.{ }^{\circ} \mathrm{C}\right)$ under low light condition $(\approx 15$ $\mu \mathrm{mol} \cdot \mathrm{m}^{-2} \cdot \mathrm{s}^{-1}$ photosynthetically active radiation for 8 to $9 \mathrm{~h}$ per day). The experimental design for each cultivar was a split plot with six replicates with five to six cuttings in each replicate. In November, each beaker was considered a replicate and each beaker held five cuttings. The intact and excised axillary buds comprised the main plots and the cytokinin treatments comprised the subplots. The cuttings were misted at weekly intervals with a spray bottle and they were inspected for root and shoot growth after 2 and 4 weeks. After 4 weeks in the rooting media, the rooted cuttings were transferred into pots and moved to a greenhouse bench with bottom heat for additional observations. Percent shoot and root emergence calculated for each replicate was transformed before statistical analysis. Transformed data were analyzed by analysis of variance using SAS (version 9.1; SAS Institute, Cary, NC) with a model that included treatments, replications, and sampling dates, and significance was tested at $P \leq 0.05$. Mean separation was determined by Student's $t$ test for significance at $P \leq 0.05$.

\section{Results and discussion}

A non-misted, enclosed system was effective in inducing adventitious root and shoot development in nonleafy, hardwood cuttings of 'Siskiyou'. Emergence of shoots occurred in high percentage of 'Siskiyou' cuttings from all collection dates (Table 1). Averaging across all treatments, rooting was $83 \%$ and $97 \%$ in cuttings propagated in November and December,

Table 1. The effect of partial bud excision and benzyladenine [0.87 $\mathrm{mm}$ (196 ppm)] application on the percentage of non-leafy floricane cuttings of 'Siskiyou' blackberry with shoot and root after $1 \mathrm{mo}$. in the enclosed environment. Buds were either left intact or the distal half to two-third removed by making a radial cut through the bud. Cuttings were stuck in rooting medium in Nov. 2009, Dec. 2009, and Jan. 2010.

\begin{tabular}{|c|c|c|c|c|c|c|c|}
\hline \multirow[b]{3}{*}{ Treatment } & & \multicolumn{6}{|c|}{ Propagation mo. } \\
\hline & & \multicolumn{2}{|c|}{ November } & \multicolumn{2}{|c|}{ December } & \multicolumn{2}{|c|}{ January } \\
\hline & & $\begin{array}{c}\text { Shoot } \\
(\%)\end{array}$ & $\begin{array}{c}\text { Root } \\
(\%)\end{array}$ & $\begin{array}{c}\text { Shoot } \\
(\%)\end{array}$ & $\begin{array}{c}\text { Root } \\
(\%)\end{array}$ & $\begin{array}{c}\text { Shoot } \\
(\%)\end{array}$ & $\begin{array}{c}\text { Root } \\
(\%)\end{array}$ \\
\hline \multirow[t]{3}{*}{ Bud excision } & Intact & 98 & 80 & 94 & 97 & 96 & 72 \\
\hline & Excised & 90 & 87 & 97 & 98 & 89 & 62 \\
\hline & Significance & NS & NS & NS & NS & NS & NS \\
\hline \multirow[t]{3}{*}{ Benzyladenine } & $0 \mathrm{~mm}$ & 95 & $97 a^{z}$ & 95 & 98 & 98 a & $83 \mathrm{a}$ \\
\hline & $0.87 \mathrm{~mm}$ & 93 & $70 \mathrm{~b}$ & 96 & 97 & $87 \mathrm{~b}$ & $50 \mathrm{~b}$ \\
\hline & Significance & NS & ** & NS & NS & ** & ** \\
\hline Bud excision $>$ & ladenine & * & NS & NS & NS & NS & NS \\
\hline
\end{tabular}

${ }^{\mathrm{z}}$ Means within the same treatment followed by the same letter are not significantly different at $P=0.05$ as determined by Student's $t$ test.

NS, ${ }^{*},{ }^{*}$ Nonsignificant or significant at $P \leq 0.05$ or 0.01 , respectively. 
respectively, and $66 \%$ in cuttings propagated in January. In 'Siskiyou' and in 'Triple Crown', adventitious roots developed mostly at the base of the axillary (Fig. 1A), but in $\approx 15 \%$ of cuttings, additional adventitious roots developed at the base of the cuttings (data not presented). Although different rooting medium (Fig. 1B) was used for each collection date, the rooting values obtained for cuttings taken in Nov. 2009, Dec. 2009, and Jan. 2010 were not statistically different $(P>0.05)$. The results suggested that the rooting percentage of cuttings taken in early winter was as good as the rooting success obtained with leafy cuttings taken in summer and rooted under intermittent mist as reported previously (Busby and Himelrick, 1999; Zimmerman et al., 1980).

In 'Triple Crown' cuttings, shoots emerged in $73 \%$ of cuttings in 4 weeks, but rooting occurred in fewer cuttings. Averaged across all treatments, rooting occurred in $27 \%$, $40 \%$, and $27 \%$ of cuttings stuck in November, December, and January, respectively (Table 2 ). The rooting results obtained for three collection dates were not statistically significant $(P>0.05)$. The rooting success of hardwood cuttings of 'Triple Crown' was as good as those reported for softwood cutting by Busby and Himelrick (1999) but slightly less than those reported by Zimmerman et al. (1980).

The use of one-node cuttings for the enclosed system maximized the quantity of cuttings that could be obtained from stock plants. The results also indicated that hardwood cuttings taken in winter can be rooted in low light conditions. Therefore, the trays can be stacked to increase the number of cuttings for rooting in a given floor space. The system used in this study appears to be an effective and efficient method for vegetative propagation of 'Siskiyou' but not for 'Triple Crown'.

Adventitious root development at the node was unaffected by excising the bud tip at all propagation dates (Tables 1 and 2). Nevertheless, partial bud removal caused callus growth at the base of the axillary bud, which may be induced to form roots with an appropriate environmental or hormone treatment. Interestingly, the cytokinin treatment increased cuttings with multiple shoot growth. Averaging across cultivars and sticking dates,
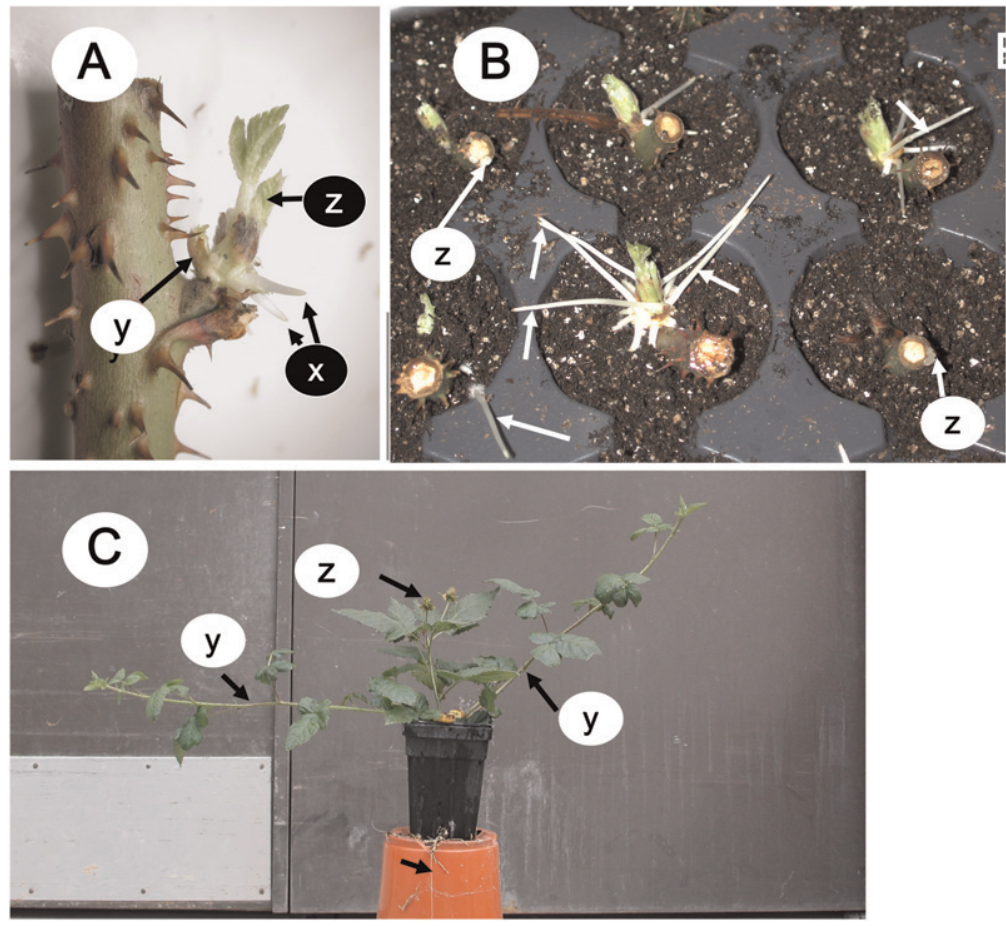

Fig. 1. One-node hardwood cuttings of 'Siskiyou' blackberry in the enclosed system and after replanting in pots and grown in the greenhouse showing the development of adventitious roots and flowering shoot. (A) After 2 weeks in the enclosed system, leaves from the main shoot $(\mathrm{z})$ and a side shoot $(\mathrm{y})$ are visible. Also, the adventitious roots $(\mathrm{x})$ are starting to emerge from the base of the axillary bud. (B) After 3 weeks in the enclosed system, adventitious roots are present at the base of the axillary bud. Note that some adventitious roots (arrow) are growing upward and out of the substrate and callus has differentiated at cut ends $(\mathrm{z})$. (C) A rooted cutting $\approx 6$ weeks after being potted and grown on a heated mat in the greenhouse. Note the upright fruiting shoot with three berries $(\mathrm{z})$, and vegetative side shoots $(\mathrm{y})$ have developed from the axillary bud. Roots have emerged through the drain hole at the bottom (arrow).

Table 2. The effect of partial bud excision and benzyladenine [0.87 $\mathrm{mm}$ (196 ppm)] application on the percentage of non-leafy floricane cuttings of 'Triple Crown' blackberry with shoot and root after 1 mo. in the enclosed environment. Buds were either left intact or the distal half to two-third removed by making a radial cut through the bud. Cuttings were stuck in rooting medium in Nov. 2009, Dec. 2009, and Jan. 2010.

\begin{tabular}{|c|c|c|c|c|c|c|c|}
\hline \multirow[b]{3}{*}{ Treatment } & & \multicolumn{6}{|c|}{ Propagation mo. } \\
\hline & & \multicolumn{2}{|c|}{ November } & \multicolumn{2}{|c|}{ December } & \multicolumn{2}{|c|}{ January } \\
\hline & & $\begin{array}{c}\text { Shoot } \\
(\%)\end{array}$ & $\begin{array}{c}\text { Root } \\
(\%)\end{array}$ & $\begin{array}{c}\text { Shoot } \\
(\%)\end{array}$ & $\begin{array}{c}\text { Root } \\
(\%)\end{array}$ & $\begin{array}{c}\text { Shoot } \\
(\%)\end{array}$ & $\begin{array}{l}\text { Root } \\
(\%)\end{array}$ \\
\hline \multirow[t]{3}{*}{ Bud excision } & Intact & 77 & 15 & 62 & 29 & $97 \mathrm{a}$ & 18 \\
\hline & Excised & 80 & 40 & 71 & 50 & $70 \mathrm{~b}$ & 16 \\
\hline & Significance & NS & NS & NS & NS & * & NS \\
\hline \multirow[t]{3}{*}{ Benzyladenine } & $0 \mathrm{~mm}$ & $63 b^{z}$ & 30 & $61 \mathrm{~b}$ & 48 & 82 & $29 \mathrm{~b}$ \\
\hline & $0.87 \mathrm{~mm}$ & $93 \mathrm{a}$ & 25 & $72 \mathrm{a}$ & 31 & 84 & $48 \mathrm{a}$ \\
\hline & Significance & ** & NS & * & NS & NS & ** \\
\hline Bud excision & yladenine & NS & NS & NS & NS & NS & NS \\
\hline
\end{tabular}

${ }^{2}$ Means within the same treatment followed by the same letter are not significantly different at $P=0.05$ as determined by Student's $t$ test.

NS, ${ }^{*},{ }^{*}$ Nonsignificant or significant at $P \leq 0.05$ or 0.01 , respectively.

$34 \%$ of cytokinin-dipped cuttings developed side shoots compared with only $22 \%$ of water-dabbed cuttings. Despite the increased shoot growth, cytokinin treatment reduced adventitious root growth. For example, after 2 weeks in the enclosed system, only $3 \%$ of 'Siskiyou' cuttings stuck in 
November and treated with cytokinin had roots compared with $80 \%$ of untreated cuttings (data not presented).

After 4 to 6 weeks in the greenhouse, the main shoot that developed from rooted cuttings with intact axillary bud ended with several flowers, but the side shoots were vegetative and grew as much as $60 \mathrm{~cm}$ (Fig. lC). A partial excision of the axillary bud is a means to eliminate the development of flowerings. All cuttings that were retained in the enclosed system for additional 4 weeks survived, suggesting that the window was broad for removing cuttings from the enclosure (data not presented). However, no significant increase in rooting was observed during their second month in the enclosed system. In a side study, one-node cuttings were placed between moistened paper towels and stored in a sealed plastic bag for 4 weeks. Many roots developed in these cuttings, but shoots did not emerge (data not presented). These observations suggest that some light is necessary for shoot growth. This technique may be of benefit for propagating cultivars that do not root well from hardwood cuttings. Cuttings can initially be stored in bags with high humidity for 2 or 3 weeks to initiate adventitious roots, and only those cuttings with roots would be transferred in trays and grown out in a heated greenhouse under mist or in an enclosed system for further development. This procedure should improve propagation and greenhouse use efficiency and reduce water use by shortening the time the cuttings are under intermittent mist.

Adventitious root formation in 'Siskiyou' and 'Triple Crown' obtained in this study was similar or better than the results of other studies using other blackberry cultivars, in which auxin treatments were applied and green or hardwood cuttings were misted intermittently. Much of the adventitious roots on cuttings placed in the enclosed system developed from the base of the axillary bud. Rooting occurred at the bud whether the node was above or in the rooting medium (Fig. IA and 1B). The enclosure system used in this experiment is straightforward and low cost. For commercial acceptance of this method, however, modifications to stock plant production techniques are necessary to comply with the voluntary certification code in some states for the propagation of caneberry planting material. According to the Washington State Department of Agriculture (2010), cuttings of caneberry plants cannot be taken from planting stock for more than 2 years and planting stock remains non-flowering.

Research by others (Busby and Himelrick, 1999; Zimmerman et al., 1980) showed that a high percentage of softwood cuttings of thornless blackberry taken in summer can be rooted under intermittent mist. The results of this study showed that a high percentage of hardwood cuttings of 'Siskiyou' taken in winter will root in an enclosed system without intermittent misting. Propagation of 'Triple Crown' by hardwood cuttings needs further research. In this study, less than $50 \%$ of 'Triple Crown' cuttings rooted in the enclosed system. In both cultivars, shoot growth occurred in high percentages of one- and twonode cuttings. Auxin treatments can improve rooting somewhat (Bray et al., 2003; Busby and Himelrick, 1999; Zimmerman et al., 1980). In these reports, auxin was applied as a dip in talc powder with IBA or as a quick 5-s dip in IBA solution. However, uniform rooting may be difficult to obtain because of the variability in the amount of the talc adhering to the base of the blackberry cuttings that tend to have smooth texture or as a quick 5-s dip in IBA solution (Hartmann et al., 1997). Perhaps the total amount of auxin reaching the base of the axillary bud where most of the adventitious roots were initiated can be improved if cuttings are soaked in more dilute auxin solution for longer periods. The enclosure technique must be refined to improve rooting of recalcitrant cultivars like Triple Crown, and utility of hormone will be further evaluated. Any propagation method for commercial distribution of plant material must produce transplants that are pest-free and meet state certification code and regulations. It is anticipated that the effectiveness, efficiency, and low cost of this enclosure approach can be used for large- and small-scale propagation of blackberry plants.

\section{Literature cited}

Bray, M.M., C.R. Rom, and J.R. Clark. 2003. Propagation of thornless Arkansas blackberries by hardwood cuttings. Discovery (Univ. of Arkansas) 4:9-13.
Busby, A.L. and D.G. Himelrick. 1999. Propagation of blackberries ( $R u b u s$ spp.) by stem cuttings using various IBA formulations. Acta Hort. 505:327-332.

Caldwell, J.D. 1984. Blackberry propagation. HortScience 19:13-15.

Erickson, E.N. 1974. Root formation in pea cuttings. III. The influence of cytokinin at different development stages. Physiol. Plant. 30:163-167.

Finn, C.E., F.J. Lawrence, B.C. Strik, B. Yorgey, and J. DeFrancesco. 1999. 'Siskiyou' trailing blackberry. HortScience 34:1288-1290.

Galletta, G.J., J.L. Maas, J.R. Clark, and C.E. Finn. 1998. 'Triple Crown' thornless blackberry. J. Amer. Pomol. Soc. 52:124-127.

Hartmann, H.T., D.E. Kester, F.T. Davies Jr., and R.L. Geneve. 1997. Plant propagation: Principles and practices. 6th ed. Prentice Hall, Upper Saddle River, NJ.

Heide, O.M. 1965. Interaction of temperature, auxin, and kinins in the regeneration ability of Begonia leaf cuttings. Physiol. Plant. 18:891-920.

Lopez-Medina, J. and J.N. Moore. 1997. Propagation of erect blackberries by floricane stem cuttings. HortScience 32:602 (abstr.).

Takeda, F., A.K. Hummell, and D.L. Peterson. 2003. Effects of cane number on yield components in 'Chester Thornless' blackberry on the rotatable cross-arm trellis. HortScience 38:377-380.

Takeda, F. and M. Wisniewski. 1989. Organogenesis and patterns of floral bud development in two eastern thornless blackberry cultivars. J. Amer. Soc. Hort. Sci. 114:528-531.

Takeda, F., B.C. Strik, D. Peacock, and J.R. Clark. 2002. Cultivar differences and the effect of winter temperature on flower bud development in blackberry. J. Amer. Soc. Hort. Sci. 127:495-501.

Thompson, E., J.R. Clark, and C.R. Rom. 2004. Propagation of thornless blackberries utilizing adventitious shoots from root cuttings. Discovery (Univ. of Arkansas) 5:93-97.

Washington State Department of Agriculture. 2010. Title 16, Chapter 16-333, Washington Administrative Code, Certification of caneberry planting stock. 14 Jan. 2011. <http://apps.leg.wa.gov/ WAC $/$ default aspx? cite $=16-333>$.

Zimmerman, R.H., G.J. Galletta, and O.C. Broome. 1980. Propagation of thornless blackberries by one-node cuttings. J. Amer. Soc. Hort. Sci. 105:405-407. 